\title{
INSTITUTIONAL STRATEGIC CONSCIOUSNESS AND ITS REFLECTIONS: RESEARCH ON QUALIFIED HOTELS IN ISTANBUL
}

\author{
Muhsin HALIS \\ Mehmet SARIISIK \\ Oguz TURKAY \\ Sakarya University, Turkey
}

\begin{abstract}
Strategic consciousness is a cognitive skill that enables firms to develop a clear vision and a system of thought based on inquiry, research, transforming values, increasing mental capabilities, etc. The success of strategic planning is also related to this phenomenon. In this study, strategic consciousnesses of hotels has been measured related to three factors, consisting of reframing, reflecting and system thinking. Consciousness construct was found to be formed by two factors in hotels: reframing and reflecting, and system thinking. These two factors have influenced the content of strategic action plans, stakeholder analysis and participation, existence of action plan, and performance measurement. Two factors of consciousness have been influenced, especially in the variation of stakeholder analysis and participation. Stakeholder analysis and participation factors have determined the level of customer satisfaction significantly.
\end{abstract}

Keywords: strategic consciousness, reframing, reflecting, system thinking, hotel industry in Istanbul.

\section{INTRODUCTION}

In last two decades, many reasons such as competitive pressures, technological developments, environmental changes, etc., have affected organizations when making healthy decisions for their future. The ways these difficulties are faced determine comprehensive decisions and results. For several years, researchers have attempted to define "strategy" and have tried to model variables; in such, activities and relations were called "strategic". As it is known, strategy is a comprehensive and integrated plan that is made for providing competitive advantages, is designated to reach desired longterm goals, and is conducted by the executive management. Chandler (1962) took in hand the concept of strategy in his early study, "Strategy and Structure", as the process of determining the organization's long-term goals and objectives as well as the process of adopting a course of action and allocating sufficient resources. Andrews (1980) defined it as the pattern of decisions in a company that determines and reveals its objectives, purposes or goals; produces the principal policies and plans for achieving those goals; and defines the range of businesses the company is to pursue. To determine how to form strategies in an organization, Mintzberg and Waters (1985) identified different strategies planned or unplanned. Researchers argued that strategy was more a pattern of action, resulting from whatever intended or unintended strategies were realized; thus, the concept of strategy means more than a plan of action. The action must be supported by awareness (Pencarelli et al., 2008), thinking (Bonn, 2005), orientation (Morgan \& Strong, 2003), and consciousness (Naktiyok et al., 2009) in order to respond to the change. Although the conceptualization had been done diversely, these notions discuss the cognitive roots of strategic planning. Consciousness was thought of as more extensive and was provided a more holistic view option with

which to analyze these roots.

The main purpose of this study is to investigate the hotel managers' thoughts about strategic consciousness. Previous studies suggested that strategic planning processes have been influenced by strategic consciousness (see Naktiyok et al., 2009). However, there are few empirical studies conducted on the determinants of strategic management in the hospitality industry, especially strategy that de- 
pends on consciousness. Thus, the purpose of the study is to assess the effects of strategic consciousness in the hospitality industry, and to investigate its influences on strategic planning. The effects of strategic planning on customer satisfaction level are also an aim for discussion in order to create a model of conscious-implementation-output flow for hotels.

\section{STRATEGIC CONSCIOUSNESS AND ITS REFLECTIONS}

Depending upon many descriptions, consciousness can be defined as a "sense of awareness of self and of the environment" (Webster's Online Dictionary, 2010). This concept has been depicted as the "ability to know" something without the use of rational thought processes or direct cognition. Another description is the capacity to know without words, or to perceive the truth without justification or cognitive interpretation, reasoning or explanation. It operates knowing that past, present and future is simultaneous. Consciousness can synthesize ideas and choices instantly. It enhances analytic consideration and puts forward insights as to timing, specific strategy and innovation. Consciousness is the key to perceiving and receiving unlimited possibilities and to providing new opportunities. Therefore, it indicates ability without rational thought in a specific time, but it consists of rationality forever. To be aware of the past, present and future are provided for deeper and extensive knowledge.

Consciousness can be evaluated as one mental function that accompanies all mental events (Webster's Online Dictionary, 2010). Thus, strategic consciousness means the mental capability of a firm that collects and re-activates all mental functions. Being strategic is about knowing what it would take to turn a vision into reality and making this work for you. In the context of strategic consciousness, being strategic is more about inquiry, arguing from analogies, reframing of experiences and knowledge gained, continuous monitoring, being adaptable, being responsive to the unexpected and being ever ready to receive opportunity. It is a state of being, not just a planning document. Being strategic is less about planning ahead and more about continuous monitoring of the environment, rapid response and fast adaptation. Being strategic then means being clear about the organization's vision and mission, being aware of the organization's resources, and incorporating both into being consciously responsive to a dynamic environment. Being strategic is vital for success in business today.

The ability to think and have consciousness strategically is critical to manage complexity and to cope with fast change in the environment. Strategic behavior involves skillful planning and management; it implies forethought, an understanding of the interdependence of actions within a social system, and a purposeful coordination of resources. Leaders who engage in strategic consciousness consider the interplay between actions and responses in light of a set of purposes - purposes that may be explicitly stated or implicit in a principal's understanding of a school and its needs (Hallinger \& McCary, 1990).

Strategic consciousness allows people to let go of old identities and the need to control, instead of making choices to be a contribution to the advancement. Strategic consciousness has allowed employees to take in a wide range of information and perceive things in a broader context. To lead a successful organization, business strategy needs to be together, with a consciousness of how different factors in the wider environment and the organization fit together. Pure consciousness alone, however, does not lead to business success. Thus, to be more successful, effective strategic planning processes must support consciousness, and mutual interaction between them must be developed. Therefore, to explain business success (customer satisfaction level was discussed in this study), one must focus on consciousness as cognitive progress and its effects on the strategic planning level. The main estimation is "strategic consciousness enhances the level of strategic planning" and "strategic planning effectiveness determines the level of customer satisfaction." According to Naktiyok et al. (2009), strategic consciousness is a structure that consists of reframing, reflecting and system thinking. By this view, these three variables have been tested as predictors of strategic consciousness.

\section{Reframing}

Reframing is a cognitive skill that enables one to see and evaluate events and facts from different perspectives (Naktiyok et al., 2005). It is to be aware of possible deficiency of within one's own way. Pisapia et al. (2005) defined the term as the ability to switch attention across multiple perspectives, frames, mental models and paradigms in order to generate new insights and options for actions. Researchers emphasized four abilities used in reframing: 
1. To suspend judgment while appropriate information is gathered.

2. To be able to identify and understand mental models, paradigms and frameworks that are being used to frame a problem, situation or issue.

3. To be able to use different mental models, paradigms and frameworks to understand one situation.

4. To review and reform one's own and others' mental models.

\section{Reflecting}

Reflecting is a capability to apply knowledge for new situation and facts. Naktiyok et al. (2005) argued that this concept means to develop some intuitive standards for next cases, within the supports of experiences. According to Pisapia et al. (2005), reflection is the ability to weave logical and rational thinking through the use of perceptions, experience and information to make judgments as to what has happened, and then creates intuitive principles that guide future actions. The five abilities used in reflection are identified, as follows (Pisapia et al., 2005):

1. To recognize why certain choices work and others do not.

2. To use double loop learning governing principles.

3. To use perceptions, experience and knowledge to understand situations and how to think about them.

4. To blend perceptions, experiences, and knowledge and analysis while taking action.

5. To use your current perceptions, experience, and knowledge, and that of others from past experience, to create an understanding of the present and the future.

\section{System Thinking}

The idea of system thinking is to see the whole and develop a holistic view in order to solve problems. The features of system that provide a basis for behaviors, relations, interactions and whole social networks have to be considered. Pisapia et al. (2005) identified the term and discussed the main abilities used in system thinking: systems thinking is the ability to see systems holistically by understanding the properties, forces, patterns and interrelationships that shape the behaviors of the systems, and provide options for actions. There are four abilities used in systems thinking:

1. To think holistically.

2. To recognize patterns and interrelationships.

3. To recognize and act upon intrinsic systems properties and specific systems archetypes.

4. To recognize and act upon the system imperatives of goal attainment, pattern maintenance, integration and adaptation.

\section{Strategic Planning}

Strategic planning has been defined as the process included in evaluating an organization and its relationships with its environment, deciding what has been useful for the company and how it may realize its objectives, and the company's strategy and decision-making processes on allocating its resources to remain successful in capital and manpower. There are some definitions about this term that reiterated by many researchers in their past investigations. Poister and Streib (1999; 311-312) defined strategic planning as "strategic management [to] develop a continuing commitment to the mission and vision of the organization, nurture a culture that identifies and supports the mission and vision, and maintain a clear focus on the organization's strategic agenda throughout all of its decision processes and activi- 
ties." According to Olsen and Eadie (1982; 4), strategic planning was a disciplined effort to produce fundamental decisions and actions that shape and guide what an organization was, what it did, and why it did it.

In short, it is a set of concepts, procedures, and tools designed to help leaders, managers, and planners think, act, and learn strategically (Bryson, 2004; 15).

In recent years, strategic management and also strategic planning have been some of the most popular investigation subjects for many researchers. In some studies, they have been taken as important tools and objectives for businesses, while affecting a company's goals in others. In such, it has been stressed that strategic planning may enhance organizational viability and its competitive forces. Ayouna and Moreob (2008) pointed out that top managers of individual business units are directly responsible for the overall process of strategic management of their businesses; the linkages between their personal characteristics and the approach toward strategy development have been yet to be understood. Strategic planning was defined by Martin (1998) as forecasting the future success of an organization by matching and aligning all, while Begun and Heatwole (1999) expressed that it could provide a framework for coordinated efforts to ensure that key stakeholders understand and were working in support of common organizational objectives.

The existing literature provides few investigations about strategic planning in the tourism and hotel industry (Litteljohn \& Roper, 1991; Crawford-Welch, 1991; Burgess et al., 1995; Slattery, 1996; Alexander \& Lockwood, 1996; Karhunen, 2008). Additionally recent research in international business and management has identified a number of institutionally derived forces that affect business strategies in a post-socialist environment through transaction costs or relational networks (Karhunen, 2008).

\section{RESEARCH METHOD AND MATERIAL}

\section{Research Approach and Process}

The purpose of the study is to assess the effects of strategic consciousness in the hospitality industry and to investigate its influences on strategic planning. A cross-sectional method was employed as a known survey method. Data were collected through a developed survey according to the past researches. The Questionnaire consisted of four parts:

[1] The factors of strategic consciousness in hotels

[2] The factors of strategic planning in hotels

[3] Customer satisfaction level as non-financial performance indicator (relatively)

[4] Demographics of participants (hotel managers)

\section{Research Instrument and Data Collection}

Data for the study were collected with a structured questionnaire from four- and five-star hotels in Istanbul and analyzed via a package statistical program. Firstly, descriptive statistics about participants (hotel managers) were shown. Later, advanced statistical analysis such as factor analysis was performed to reduce a great number of variables related to strategic awareness that reflected strategic operations as outputs of strategic awareness. The obtained data were classified by using principal component analysis. Furthermore, Regression Analysis was done.

A 20-item scale questionnaire instrument was developed, based on the work of Naktiyok et al. (2009) and Pisapia et al. (2005) to investigate the levels of strategic thinking, and a 30-item scale for strategic planning activities was adopted from Naktiyok et al. (2009). As a dependent variable, the level of customer satisfaction in relations with industrial levels was measured with an item. Naktiyok et al. (2009) measured strategic thinking within the frame of three variables (reframing, reflecting and system thinking), as referred to by Pisapia et al. (2005); furthermore, strategic planning with given five variables (intuitional thinking, strategy base and action plan, environment analysis, knowledge manage- 
ment and strategic control) from some strategic planning tool kits and self-assessment questionnaires. The items for strategic thinking were obtained from Naktiyok et al. (2009) by the control and redesign from Pisapia et al. (2005) and items for strategic planning from Naktiyok et al. (2009) without any redesign process. Applicants indicated agreement on a five-point scale, ranging from 1-strongly disagree to 5-strongly agree. The item for customer satisfaction level indicated "level of satisfaction" opposite of industrial averages.

\section{The Population and Sampling}

The research population of the sample consisted of managers who were employed in qualified (fourand five-star hotels) hotels in Istanbul. Data were collected from 71 hotels. According to Statistics of Accommodation Establishments published by the Ministry of Culture and Tourism, there were 55 five -star and 103 four-star hotels located in Istanbul by the year 2008 (Republic of Turkey Ministry of Culture and Tourism, 2009).

\section{RESEARCH FINDINGS}

In the data analysis phase of the study, obtained data from hotels were analyzed by using descriptive and inferential statistical methods. Before the analysis for the study at hand, collected questionnaire forms were studied, and questionnaire that were carelessly done were removed. Then, the remaining polls were evaluated.

\section{Descriptive Statistics about Participants}

150 questionnaires were sent out to hotels, and 71 hotels responded. $18 \%$ of participants were female, while $78 \%$ of them were male. $21 \%$ worked as a top manager while $66 \%$ worked as a mid-level manager. $6 \%$ of them had a mid-school education, $35 \%$ had a two-year degree, $47 \%$ percent had a high school education, and $10 \%$ had a master or doctoral degree. According to their age categories, about $1 \%$ was under $25,30 \%$ were $26-30$ years old, $24 \%$ were $31-35$ years old, and $17 \%$ of them were above the forty. All participants had management experience; 30\% had 1-4 years, $28 \%$ had 5-8 years, $14 \%$ had 9-12 years, and $16 \%$ had more than 13 years. In the context of total job experiences, $17 \%$ of them had 1-4 years, $20 \%$ had 5-8 years, $16 \%$ had $9-12$ years, and $45 \%$ percent had more than thirteen years (Table 1).

Table 1: Demographics of Survey Voters

\begin{tabular}{|l|r|r|l|r|r|}
\hline Gender & \multicolumn{1}{|c|}{ N } & \multicolumn{1}{|c|}{$\%$} & Position & N & \multicolumn{1}{c|}{ \% } \\
\hline Female & 13 & 18,3 & Top Manager. & 15 & 21,2 \\
Male & 55 & 77,5 & Mid-level Manager & 48 & 67,6 \\
Missing & 3 & 4,2 & Missing & 8 & 11,2 \\
\hline Education & & & Job Experience as Manager & & \\
\hline Mid-level & 4 & 5,6 & $1-4$ years & 26 & 36,6 \\
Under graduated & 25 & 35,2 & $5-8$ years & 20 & 28,2 \\
Graduation & 34 & 47,9 & $9-12$ years & 10 & 14,1 \\
Master \& Doctorate & 7 & 9,9 & $13+$ years & 11 & 15,5 \\
Missing & 1 & 1,4 & Missing & 4 & 5,6 \\
\hline Age & & & Job Experience in Total & & \\
\hline-25 & 1 & 1,4 & $1-4$ years & 12 & 16,9 \\
$26-30$ & 21 & 29,6 & $5-8$ years & 11 & 19,7 \\
$31-35$ & 17 & 23,9 & $9-12$ years & 32 & 45,5 \\
$36-40$ & 16 & 22,5 & $13+$ years & 2 & 2,8 \\
$40+$ & 11 & 16,9 & Missing & & \\
Missing & 4 & 5,6 & &
\end{tabular}




\section{Findings about Strategic Consciousness}

It is very crucial to gather information via a valid scale and test its structural validity by factor analysis. For this purpose, the strategic thinking items and strategic planning items were tested with factor analysis separately. Principal component analysis, with varimax rotation, was used to assess how the 20 items were grouped for the replies on strategic consciousness. Three of the items were either cross loaded or had low scores $(<, 40)$ in the analysis; they were excluded to clearly identify the structure. The result of Keiser-Meyer-Olkin (KMO) test for sampling adequacy was 0,896, which supported the coherence of data for factor analysis. The factor analysis indicated two factors with eigenvalues greater than 1 , and these two factors explain $64,991 \%$ of total variances.

Table 2: Dimensions of Strategic Consciousness

\begin{tabular}{|l|c|c|c|c|}
\hline \multicolumn{1}{|c|}{ Factors } & & & \\
& & & \\
& & & \\
\hline Reframing and Reflecting & & & \\
\hline Consideration of using information gathered by experience, in the solution of the &, 827 & & & \\
problems. &, 827 & & \\
The causes of error and success were searched. &, 806 & & \\
"Why" was asked frequently in order to understand problems. &, 784 & & \\
It was requested from employees that they to be aware of relations between diverse &, 761 & & \\
information. &, 745 & & \\
We have a consciousness to use different perspectives against complex problems. &, 718 & & \\
Consideration of the effects of "institutional consciousness", while searching roots \\
of problems.
\end{tabular}

NOTE: Principal Components Factor Analysis with Varimax Rotation. Kaiser-Meyer-Olkin Test Value: ,896, Bartlett's Test of Sphericity: p>.000; $X^{2}$ : 901,238, df: 136; Total Variance Explained: \% 64,991; Voting Categories: 1:Strongly Agree - 5: Strongly Not Agree.

Table 2 shows the item loadings of each factor along with their respective eigenvalue, percent of variance explained and Cronbach alpha's of factors. Reframing \& reflecting factor consisted of 10 items and explained $35.550 \%$ of the total variance. System thinking factor was comprised of 7 items and explained $29,441 \%$ of total variation in the data. Reframing, system thinking and reflecting were three factors expressed as dimensions of strategic thinking by Pisapia et al. (2005) and also Naktiyok et al. (2009). In the sample of hotels, it was diversified as a structure with two factors: reframing \& reflecting, and system thinking. This result indicated that the scale of strategic thinking was adequate for hotel population, but with a structural differentiation. For hotels, we have to consider the concept of strategic consciousness within two factors/dimensions. 


\section{Reflections of Strategic Consciousness}

To assess the structure of strategic planning, factor analysis was implemented. Principal component analysis, with varimax rotation, was used to assess how the 30 items were grouped for the ratings on strategic planning. 14 of the total items were either cross loaded or had low scores $(<, 40)$ in the analysis, thus, they were excluded. The result of the Keiser-Meyer-Olkin (KMO) test for sampling adequacy was 0,866 , which supported the congruence of data for factor analysis. The factor analysis indicated four factors with eigenvalues greater than 1 , and the ratio of variance explained by these four factors is $72,351 \%$ (Table 3 ).

\section{Table 3: Dimensions of Strategic Consciousness Reflections}

\begin{tabular}{|c|c|c|c|c|}
\hline Factors & 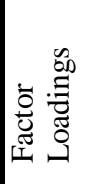 & 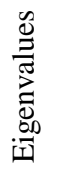 & 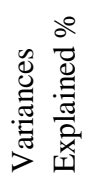 & 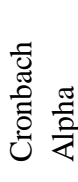 \\
\hline The Content of Strategic Action Plan & & 3,37 & 21,06 & ,874 \\
\hline Action plan clarifies aims and activities obviously & 824 & & & \\
\hline Employee knows how and from where they can gain information that they need & ,744 & & & \\
\hline Resources are identified for action plan &, 732 & & & \\
\hline Qualitative and quantitative estimation techniques are utilized for strategic planning & 663 & & & \\
\hline We have a vision and mission statement & 650 & & & \\
\hline Stakeholder Analysis and Participation & & 2,97 & 18,56 & ,872 \\
\hline The communication channels were identified for every stakeholder groups & 874 & & & \\
\hline The needs and demands of stakeholders were defined & ,776 & & & \\
\hline All of related employees were involved in planning process & 671 & & & \\
\hline In planning process, feedback was gained &, 564 & & & \\
\hline It had been determined the time periods for each action in action plan &, 559 & & & \\
\hline Existence of Action Plans & & 2,67 & 16,69 & ,807 \\
\hline We have a plan for medium-term (1-3 years) & 820 & & & \\
\hline We have a long-term plan (for after 3 years) & ,794 & & & \\
\hline We have a short term plan (for the period of 1 year) & ,755 & & & \\
\hline Performance Measurement & & 2,56 & 16,02 &, 812 \\
\hline $\begin{array}{l}\text { It is defined and well known how the results of controls will be analyzed and re- } \\
\text { ported } \\
\text { Performance outcomes were scanning and analyzing regularly } \\
\text { The targets of our firm are identified and could be measured as quantitative }\end{array}$ & $\begin{array}{l}, 850 \\
, 845 \\
, 660\end{array}$ & & & \\
\hline
\end{tabular}

NOTE: Principal Components Factor Analysis with Varimax Rotation,. Kaiser-Meyer-Olkin Test Value: ,866; Bartlett's Test of Sphericity: p>.000; X²: 692,454, df: 120; Total Variance Explained: \% 72,351; Voting Categories: 1:Strongly Agree - 5: Strongly Not Agree.

The content of the strategic action plan, stakeholder analysis and participation, existence of action plan, and performance measurement factors are identified. The content of the strategic action plan factors consisted of five items and explained $21,06 \%$ of the total variance. Stakeholder analysis and participation factors comprised five items and explained $18,56 \%$ of total variation in the data. Existence of action plan factor consisted of three items, which explain $16,69 \%$ of total variances. Performance measurement factors also consisted of three items, explaining $16,02 \%$ of variances. This is the situation of how sampling hotels perform strategic planning, and which determinations are affected in the planning process.

Internal consistency reliabilities for factors were generally high, indicating respondents answered these items consistently. 
To investigate the effects of strategic consciousness factors on strategic planning factors (Table 4) and strategic planning factors on the level of customer satisfaction (Table 5), regression analysis was conducted. To determine these relationships, the related factors entered into the equation together, and factors which have a significant effect are highlighted.

\section{Table 4: Regression Analysis Results for the Effects of "Strategic Thinking" Factors on "Strategic Planning" Factors}

\begin{tabular}{|c|c|c|c|c|c|c|c|}
\hline Dependent Variable & Predictors & Beta & $\begin{array}{c}t \\
\text { value }\end{array}$ & $\begin{array}{c}p \\
\text { value }\end{array}$ & $\mathbf{R}^{2}$ & $\begin{array}{c}\text { F } \\
\text { Change }\end{array}$ & Sig. \\
\hline \multirow{2}{*}{$\begin{array}{l}\text { Content of Str. Action } \\
\text { Plan }\end{array}$} & Reframing \& Reflecting &, 176 & 1,681 & 0,097 & ,617 & 54,789 & 000 \\
\hline & System thinking & ,653 & 6,254 & 0,000 & & & \\
\hline \multirow{2}{*}{$\begin{array}{l}\text { Stakeholder Analysis } \\
\text { And Participation }\end{array}$} & Reframing \& Reflecting & $\overline{532}$ & 5,082 & 0,000 & ,616 & 54,464 & $\overline{, 000}$ \\
\hline & System thinking &, 315 & $3, \mathbf{3 , 4}$ & $\mathbf{0 , 0 0 4}$ & & & \\
\hline \multirow{2}{*}{$\begin{array}{l}\text { Existence of Action } \\
\text { Plan }\end{array}$} & Reframing \& Reflecting &,- 087 &,- 721 &, 474 & ,491 & 32,846 & ,000 \\
\hline & System thinking &, 759 & 6,301 &, 000 & & & \\
\hline \multirow{2}{*}{$\begin{array}{l}\text { Performance Meas- } \\
\text { urement }\end{array}$} & Reframing \& Reflecting &, 857 & 8,693 &, 000 & ,659 & 65,626 & $\overline{, 000}$ \\
\hline & System thinking &,- 068 &,- 686 & ,495 & & & \\
\hline
\end{tabular}

System thinking has a significant affect on variance in content of strategic action plan $(p<0,01)$. Rsquare shows this is a strong effect and to explain the variation of dependent variables, variation of system thinking has a strong effect. Each two independents have determined effect significantly on the explanation of variations on stakeholder analysis and participation $(\mathrm{p}<0,01)$. R-square is absolutely high. As a dependent variable, existence of action plan is determined by system thinking significantly $(\mathrm{p}<0,01)$ with the R-square value of ,49. The variation on performance measure factors is also explained by variation on reframing \& reflecting factor significantly $(\mathrm{p}<0,01)$ with a high $\mathrm{R}$-square rate of , 65 .

These results show how such two concepts / structure are tied to each other and significance of identified relations within the dimensions of them. In this framework, it may assert a proof for the relationship of these dimensions. Further, to advocate the effect-cause relation between these dimensions is meaningful.

\section{Table 5: Regression Analysis Results for the Effects of "Strategic Planning" Factors on the Level of Customer Satisfaction}

\begin{tabular}{|c|c|c|c|c|c|c|c|}
\hline $\begin{array}{l}\text { Dependent } \\
\text { Variable }\end{array}$ & Predictors & Beta & $\begin{array}{c}\text { t } \\
\text { value }\end{array}$ & $\underset{\text { value }}{p}$ & $\mathbf{R}^{2}$ & $\begin{array}{c}\text { F } \\
\text { Change }\end{array}$ & Sig. \\
\hline \multirow[t]{4}{*}{$\begin{array}{l}\text { Level of customer } \\
\text { Satisfaction }\end{array}$} & $\begin{array}{l}\text { Content of Str. Action } \\
\text { Plan }\end{array}$ &,- 045 &,- 297 & ,767 & 270 & 7,095 & ,000 \\
\hline & $\begin{array}{l}\text { Stakeholder Analysis And } \\
\text { Participation }\end{array}$ & ,587 & 3,869 & ,000 & & & \\
\hline & Existence of Action Plan &, 071 &, 543 &, 589 & & & \\
\hline & $\begin{array}{l}\text { Performance } \\
\text { Measurement }\end{array}$ &,- 061 &,- 472 & ,639 & & & \\
\hline
\end{tabular}

Three strategic planning factors (the content of strategic action plan, existence of action plan, and performance measurement) did not have any significant influence on the level of customer satisfaction $(p>0,05)$. Only stakeholder analysis and participation factors significantly explained the variation in dependent variable at the 27 percent level $\left(\mathrm{R}^{2}\right)$.

Similar significant relations were found by Naktiyok et al. (2009). Although there are differences in factors that determine the construct of strategic planning, the match between two studies between the strong effect from strategic consciousness and strategic planning is noteworthy. Results indicated that in hotels, there is a strong dependency between planning and consciousness. Planning performs a key role to capture the satisfaction of a customer. Findings are shown below in Figure 1. 


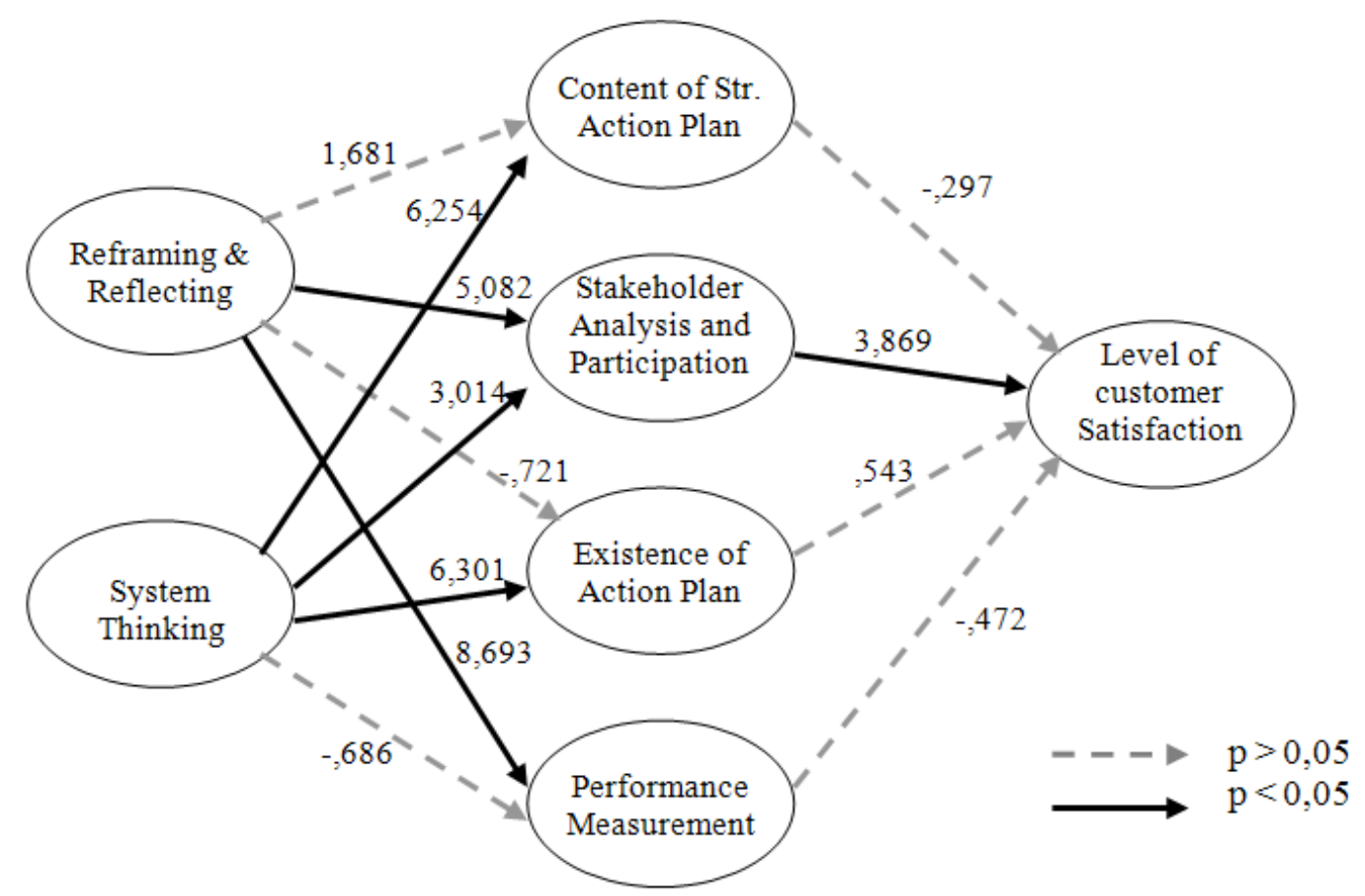

Figure 1: The Model of Study with $t$ Values

\section{CONCLUSION}

This study investigated the effects of strategic consciousness on strategic planning and the effects of strategic planning on customer satisfaction. Initial results indicated that the reframing \& reflecting factor and system thinking factor explained significant variances in both content of strategic action plan, stakeholder analysis and participation, existence of action plan, and performance measurement. To explain the variations in content of strategic action plan and existence of action plan, only system thinking created an effect, while the performance measurement factor was determined by only reframing \& reflecting. This is the more noteworthy result: namely, that both factors of thinking have strong power to explain the variation in stakeholder analysis and participation. On the other hand, the level of customer satisfaction is explained only by stakeholder analysis and participation, significantly.

We can express that for the qualified hotels, reframing \& reflecting and system thinking factors determine strategic planning activities, especially stakeholder analysis and participation, and these variables have crucial contribution to the customer satisfaction level of a firm.

In terms of creating customer satisfaction, these results suggest that these two dimensions of reframing \& reflecting and system thinking must be considered together. The factor of reframing \& reflecting or system thinking alone has no significant effect and no potential to crate adequate output. In this case, the structure of strategic consciousness, inspired by the dimensions of reframing \& reflecting and system thinking, provides a holistic view of strategic management in terms of comprehensive assessments. This structure has a very strong effect on effective strategic application creating customer satisfaction. In addition, the emergence of stakeholder analysis and participation as the strategic applications leading to customer satisfaction requires re-evaluation of the effect of strategic management activity in the hotel businesses. Existence and content of strategic action plans and performance measurement applications are inadequate to explain customer satisfaction. The inconsistency of some strategic application areas to explain customer satisfaction level may be related to requisites of a competitive environment, which required some critical application without any strategic preparation. It is possible to think that hotel companies can respond to the changes in the market without any formal strategic harmonization in the fields of existence, as well as content of strategic action plans and performance measurement. Furthermore, stakeholder analysis and participation is an area in which it is necessary to develop some applications in order to create customer satisfaction. 


\section{REFERENCES}

Alexander, N. and Lockwood, A. (1996), Internationalization: a Comparison of the Hotel and Retail Sectors, Service Industries Journal, 16(4), pp.458-73.

Andrews, K. (1980), The Concept of Corporate Strategy, 2nd Edition. Dow-Jones Irwin.

Ayouna, B.M. and Moreob, P.J. (2008), The Influence of the Cultural Dimension of Uncertainty Avoidance on Business Strategy Development: A Cross-National Study of Hotel Managers, International Journal of Hospitality Management, 27, pp. 65-75.

Begun J, and Heatwole KB. (1999), Strategic Cycling: Shaking Complacency in Healthcare Strategic Planning, Journal of Healthcare Management, 44, pp. 339-352.

Bonn, I., (2005), Improving Strategic Thinking: a Multilevel Approach, Leadership \& Organization Development Journal, 26(5), pp. 336-354.

Bryson, J. (2004), Strategic Planning for Public and Nonprofit Organizations, 3rd Edition. JosseyBass San Francisco, USA.

Burgess, C., Hampton, A., Price, L. and Roper, A., (1995), International Hotel Groups: What Makes Them Successful?, International Journal of Contemporary Hospitality Management, 7 (2/3), pp. 74 80 .

Chandler, A.D. (1962), Strategy and Structure, MIT Press, Cambridge, USA.

Crawford-Welch, S., (1991), International Marketing in the Hospitality Industry. In: Teare, R., Boer, A. (Eds.), Strategic Hospitality Management, pp. 166-193, Cassell, London, England.

Hallinger, P., Mc Cary, C.E. (1990), Developing the Strategic Thinking of Instructional Leaders, The Elementary School Journal, 91(2), pp. 89-105.

Karhunen, P. (2008), Managing International Business Operations in a Changing Institutional Context: the Case of the St. Petersburg Hotel Industry, Journal of International Management, 14, pp. 28 45 .

Litteljohn, D., Roper, A., (1991), Changes in International Hotel Companies' Strategies. In: Teare, R., Boer, A.(Eds.), Strategic Hospitality Management, pp. 194-212, Cassell, London.

Martin M.(1998), Achieving the Right Balance with Strategic Planning, Nursing Management, 29(5), pp. 30-31.

Mintzberg, H. and Waters, J.A. (1985), Of Strategies, Deliberate and Emergent, Strategic Management Journal, 6, pp. 257-272.

Morgan, R.E., and Strong, C.A. (2003), Business Performance and Dimensions of Strategic Orientation, Journal of Business Research, 56, pp. 163-176.

Naktiyok, A., Karabey, C.N. and Timuroğlu, M.K. (2009), Stratejik Bilinç: İşletmelerin Stratejik Bilinç Düzeyinin İncelenmesi, İmaj Yayınevi, İstanbul.

Olsen, J.B., Eadie, D.C. (1982), The Game Plan: Governance with Foresight, Washington Council of State Planning Agencies, Washington DC.

Pencarelli, T., Savelli, E. and Splendiani, S. (2008), Strategic Awareness and Growth Strategies in Small Sized Enterprises, 8th Global Conference on Business \& Economics, October 18-19th, 2008, Florence, Italy. 
Pisapia, J., Reyas-Guerra, D. and Coukos-Semmel, E. (2005), Developing the Leader's Strategic Mindset: Establishing the Measures, Leadership Review, 5, pp. 41-68.

Poister, T.H., and Streib, G., (1999), Strategic Management in the Public Sector: Concepts, Models and Processes, Public Productivity and Management Review, 22, pp. 308-25.

Webster's Online Dictionary, (2010), http://www.websters-online-dictionary.org/definition/ consciousness (accessed, 04.15.2010). 